\title{
A Decision-Analytic Feasibility Study of Upgrading Machinery at a Tools Workshop
}

\author{
M. L. Chew Hernández \\ Dept. of Grad. Studies and Research \\ Tech. of High Studies of Coacalco \\ México City, México \\ mchew@tesco.edu.mx
}

\author{
E. K. Velázquez Hernández \\ Dept. of Industrial Engineering \\ Tech. of High Studies of Chalco \\ Chalco, México \\ ing.evelazquez@yahoo.com.mx
}

\author{
S. León Dominguez \\ Dept. of Industrial Engineering \\ Tech. of High Studies of Chalco \\ Chalco, México \\ chavalol@msn.com
}

\begin{abstract}
This paper presents the evaluation, from a Decision Analysis point of view, of the feasibility of upgrading machinery at an existing metal-forming workshop. The Integral Decision Analysis (IDA) methodology is applied to clarify the decision and develop a decision model. One of the key advantages of the IDA is its careful selection of the problem frame, allowing a correct problem definition. While following most of the original IDA methodology, an addition to this methodology is proposed in this work, that of using the strategic Means-Ends Objective Network as a backbone for the development of the decision model. The constructed decision model uses influence diagrams to include factual operator and vendor expertise, simulation to evaluate the alternatives and a utility function to take into account the risk attitude of the decision maker. Three alternatives are considered: Base (no modification), CNC (installing an automatic lathe) and CF (installation of an automatic milling machine). The results are presented as a graph showing zones in which a particular alternative should be selected. The results show the potential of IDA to tackle technical decisions that are otherwise approached without the due care.
\end{abstract}

Keywords-decision analysis; equipment replacement; integral decision analysis; maximum expected utility

\section{INTRODUCTION}

This work presents a study of the feasibility of the inclusion of automated equipment into an existing metal manufacturing workshop located near México City. The feasibility analysis is approached from a Decision Analysis (DA) perspective. DA is a discipline which aims to bring clarity, insight and definition to messy decision situations [1-3], and has been viewed as a mixture of Systems Analysis and Decision Theory [1]. It's usage for decision making guarantees the satisfaction of a set of desiderata (axioms) of rational choice [4].

In the context of DA, several methodologies for problem analysis have been proposed, as is the case of the PrOACT [5], the Integral Decision Analysis (IDA) [2] and Value Focused Thinking (VFT) [6]; similar methodologies are discussed in [7]. These methodologies aim to convert an initially blurry situation (in which the stakeholders don't know exactly which consequences they care about or what can be done), into a structured decision model, in which alternatives and objectives have been clearly defined and measured [7].

The IDA consists of the following steps: 1) Problem Framing; 2) Analysis of Objectives; 3) Creation of Alternatives; 4) Identifying Uncertainties; 5) Decision Modeling; 6) Alternative evaluation; 7) Alternative selection and 8) Implementation. A distinct feature of the IDA is its careful determination of the decision frame, involving the creation of several frames of different sizes and emphases, using a graphic tool called diagram of decision frames.

There is a vast body of work related to the problem of finding an optimal replacement policy of industrial machinery [8-17]. A more complicated problem arises when incorporating the effects of technological change [18-20], inflation and taxes [21], a limited budget [22], imperfect repairs [23-24] or warranties from the equipment supplier [25-27]. Other researchers have approached the problem through fuzzy models [28-29] or treated the replacement of several equipments [3132]. The consideration of several objectives can be found in [33-39] while the introduction of risk attitude is shown in [40].

The decision treated here is whether or not to include new equipment at a workshop, and it can be considered equivalent to the problem of determining a policy of equipment replacement. However, the above mentioned research starts with a problem that is already structured, that is, objectives and alternative courses of action are taken as a given. Related to this, a four-step method for selecting a model for a replacement problem is shown by Fraser and Posey [41] while Hart and Cook [42] propose a systematic approach to the decision process with stages of objective identification, indicators of achievement, alternatives and problems of implementation. These methodologies, however, do not treat problem framing explicitly and don't take advantage of any of the wellestablished tools of the DA discipline.

By contrast, in a real life situation, once the idea of replacing equipment comes to mind, the engineer should proceed to carefully define a decision frame for the situation, so relevant objectives and alternatives are uncovered. These steps are omitted in the previous works and are presented here, as they are part of the IDA methodology. Also, in this work, 
relevant uncertain knowledge from the plant engineers and vendors are expressed as subjective probabilities and incorporated to the model. In this respect, except for Arueti and Okrent [39], none of the previous authors explicitly use subjective probabilities in the decision.

Finally, while this work follows the original IDA methodology for the most part, the IDA methodology is here expanded by adding the usage of the strategic MeansObjectives Network as a map for decision-model building. To the best of our knowledge, there are no reports of the application of the IDA, or other DA methodology with a similarly careful procedure for problem framing, to an industrial equipment replacement problem.

\section{PROBLEM STATEMENT}

The workshop under study is located near the town of Chalco, México. It produces several types of iron and steel tools: manual and bench drills, vises, clamps, etc. Its customers are mainly local carpenters and the nearby wood furniture industry. The main concern of the manager is a perceived low efficiency in the processing of bench vises, which happens to be the top seller product of the company. One proposal for improving this situation is to substitute old equipment with modern one, thus allowing operation with fewer workers and an increased productivity, as the modern machinery is more automated. Several issues need to be settled so the problem can be modeled correctly

1. The metric over which the modifications should be evaluated: It can be productivity, production costs or profits. The adequate metric depends on the manager's objectives.

2. The modifications that are to be considered when evaluating each proposal (i.e. are changes in inventory or layout to be considered in the decision?)

3. Are there any uncertainties that should be considered in the model? If so, the stakeholder's dislike of uncertainty should be introduced in the model.

In the following we apply the IDA steps to the problem, showing how it helps to clarify the decision. All shown tables and figures are the authors' own production.

\section{DEVELOPMENT AND RESULTS}

\section{A. Problem Framing}

In order to define a decision frame (what to decide and with which objectives), several frames should be explored. This can be conveniently done using a frames diagram. The construction of this diagram starts with the Base frame, which represents the current understanding of the decision situation, and then several other frames are defined by changing the amplitude and emphasis of the Base frame. Figure 1 shows a decision frames diagram, whose parts are explained below.

Base Frame: The trigger of the decision is the idea of automating the manufacture process, thus this frame is stated as: Deciding the automation of the manufacture process. It comprises the decision of whether or not to automate, and the type and size of the new machines. Its objective is to maximize the plant productivity.

Narrow Frames E1 and E2: The decision frame E1 is Deciding the degree and extent of the automation and E2 is Deciding the equipment provider. The objective of E1 is to maximize productivity and that of E2 is to minimize the time and costs involved in fixing possible equipment failures.

Wide Frame A1: Deciding about improving the manufacture process contains the base frame plus other alternatives, like modifications of inventory, staff, policies of inspection and outsourcing. The objective of this frame is to maximize product quality and to minimize costs.

Frames B1, B2, B3, B4 and B5: These frames are contained into A1, so their amplitude is similar to that of the Base Frame but their emphases are different: B1 emphasizes layout, B2 inspection, B3 staff, B4 inventory and B5 outsourcing. The objectives of B1-B5 are means of the objective of $\mathrm{A} 1$, related to the scope of each frame.

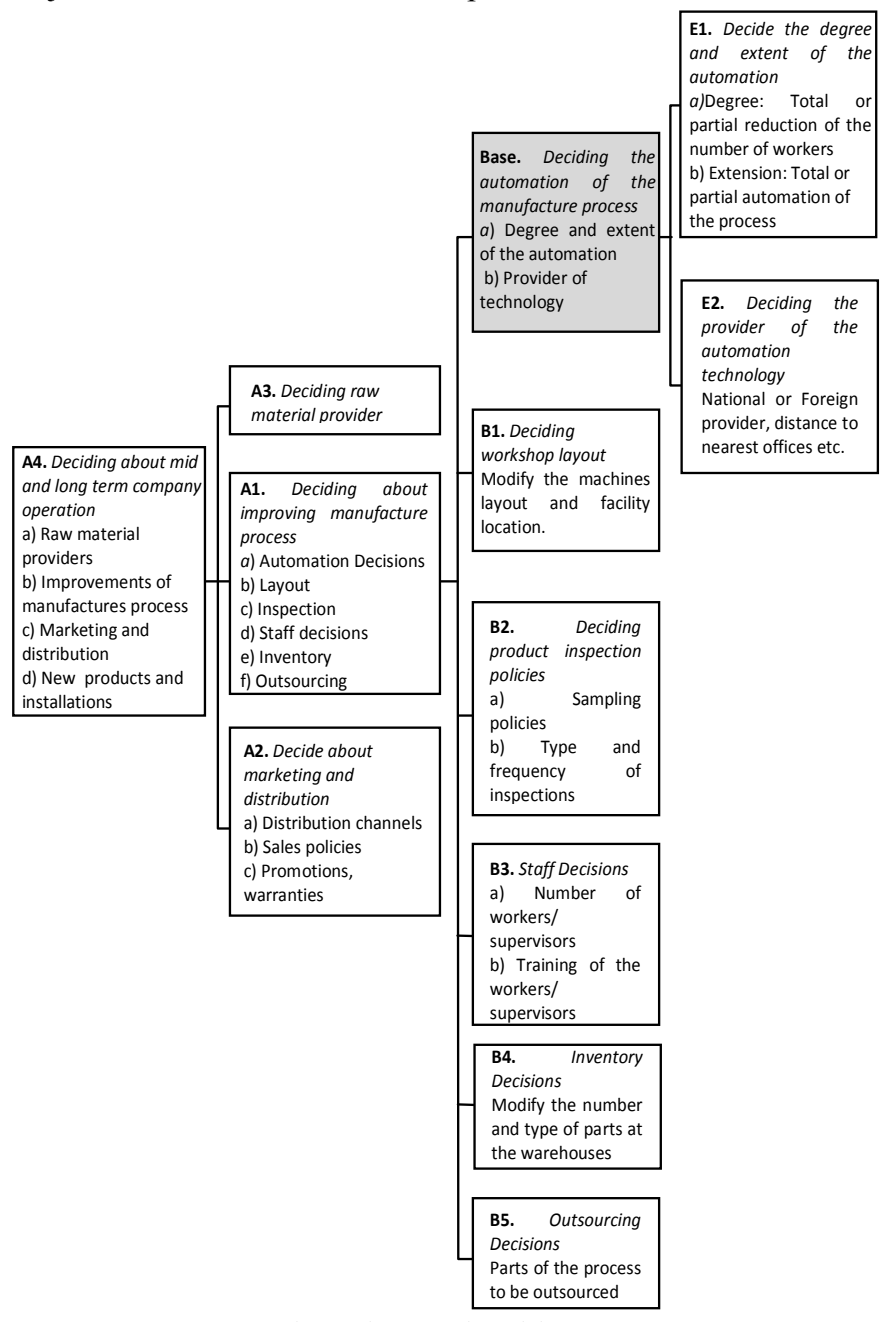

Fig. 1 Diagram of Decision Frames

Wide Frames A2 and A3: These frames shift the focus to different aspects of plant operation. A3 is Decide about raw material procurement and A2 is Decide marketing and 
distribution policies. The objectives of $\mathrm{A} 3$ are to minimize purchase costs, maximize availability and quality of raw material while those of $\mathrm{A} 2$ are to maximize sales and minimize marketing and distribution costs.

Wide Frame A4: A4 is the widest frame to consider, including frames $\mathrm{A} 1, \mathrm{~A} 2$ and $\mathrm{A} 3$ plus additional decisions, like the installation of more workshops and new product development. A4 objective is to maximize profits.

Once the Decision Frames Diagram is complete, the generated frames are analyzed. A key element of our problem is that we haven't decided whether or not to automate the process, and the automation will proceed only if it has a reasonable chance of generating economic benefits. Thus we discard the narrow frames E1 and E2, as these assume that it has been decided to automate the process.

The objective of the base frame is to increase productivity. While automating the process may increase productivity, the costs of the new equipment may outbalance the economic benefits of that increase. This would be an unacceptable scenario for the stakeholders, so the objective of the base frame is inadequate, as it doesn't refer to costs.

Frame A1 objective (maximize quality and minimize costs) is more appropriate than the objective of the Base Frame. However, not all the decisions of A1 are to be considered in the present problem: we are not allowed to change inventory, inspection or outsourcing. By pruning the decisions of A1, we produce the frame $\mathrm{A} 1 *$ which has the same objective of A1 but only decisions in the context of our problem (Figure 2 ). A $1 *$ is not yet adequate, as the decisions should be assessed by their economic implications and $\mathrm{A} 1 *$ has the objective of maximizing quality and minimizing costs. A4 has the adequate objective (maximize profits) but the decisions included in it are too wide. We thus define A4*, eliminating the decisions of A4, not included in $\mathrm{A} 1 *$. The decision frame to be used $\mathrm{A} 4 *$, shown in Figure 3.

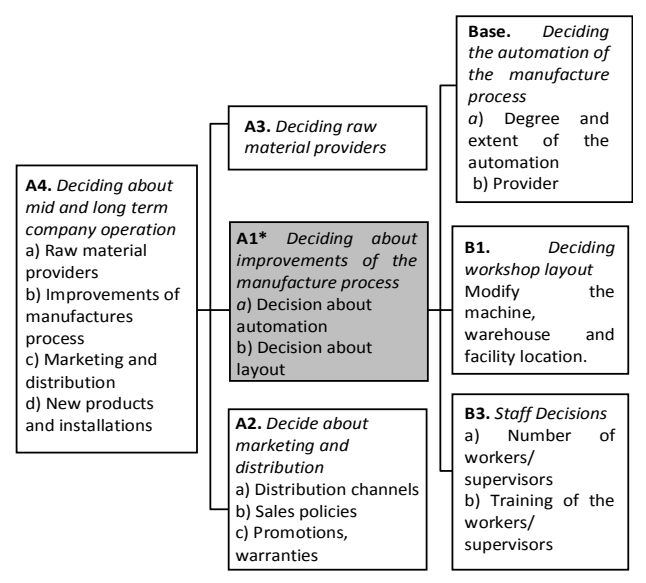

Fig. 2 Reduced Diagram of Decision Frames

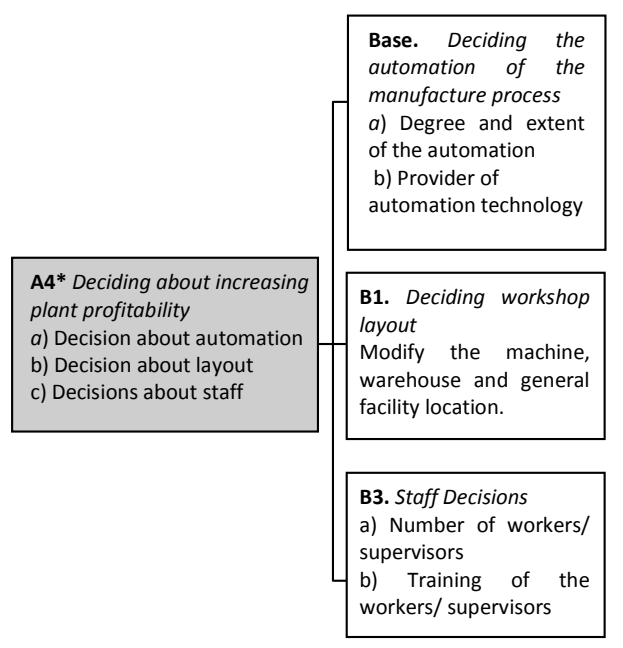

Fig. 3 Final Decision Frame

\section{B. Objective Analysis}

The first stage of the clarification of objectives is their identification [6]. To do so we begin with a "wish list" that provides the following 19 objectives

1. Maximize profits

2. Minimize total costs

3. Maximize incomes

4. Maximize sales

5. Maximize product quality

6. Minimize the number of jobs that need re-work

7. Maximize productivity

8. Minimize process times

9. Minimize transport time

10. Minimize delivery times

11. Minimize raw material waste

12. Optimize facility lay-out

13. Minimize required man-hours

14. Minimize inventory costs

15. Minimize inspection cost

16. Maximize market share

17. Maximize competitiveness of company

18. Maximize skill of work force

19. Minimize delays in product delivery

One of the most important steps in a DA approach to problem solving, is to understand the relationships among the identified objectives. The objectives that are important by themselves are called Fundamental Objectives, and are organized into a hierarchy shown in Figure 4. The objectives of the wish list that are not fundamental should either be 
equivalent to a fundamental objective, or be a mean to accomplish one. In this latter is true they are called Means Objectives and are structured in the Mean-End Objectives Network of Figure 5.

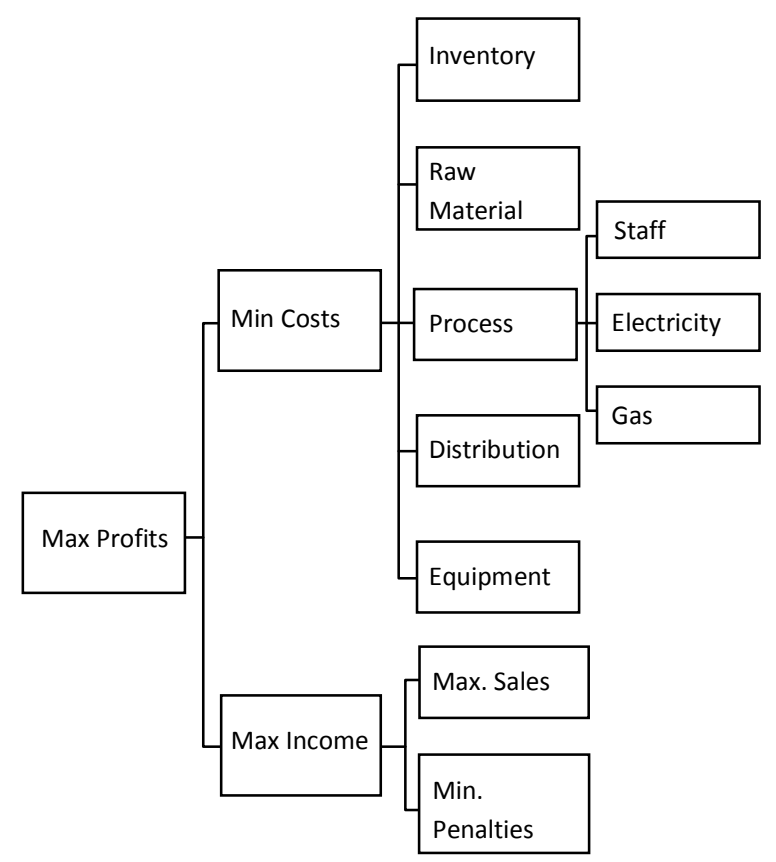

Fig. 4 Hierarchy of fundamental Objectives

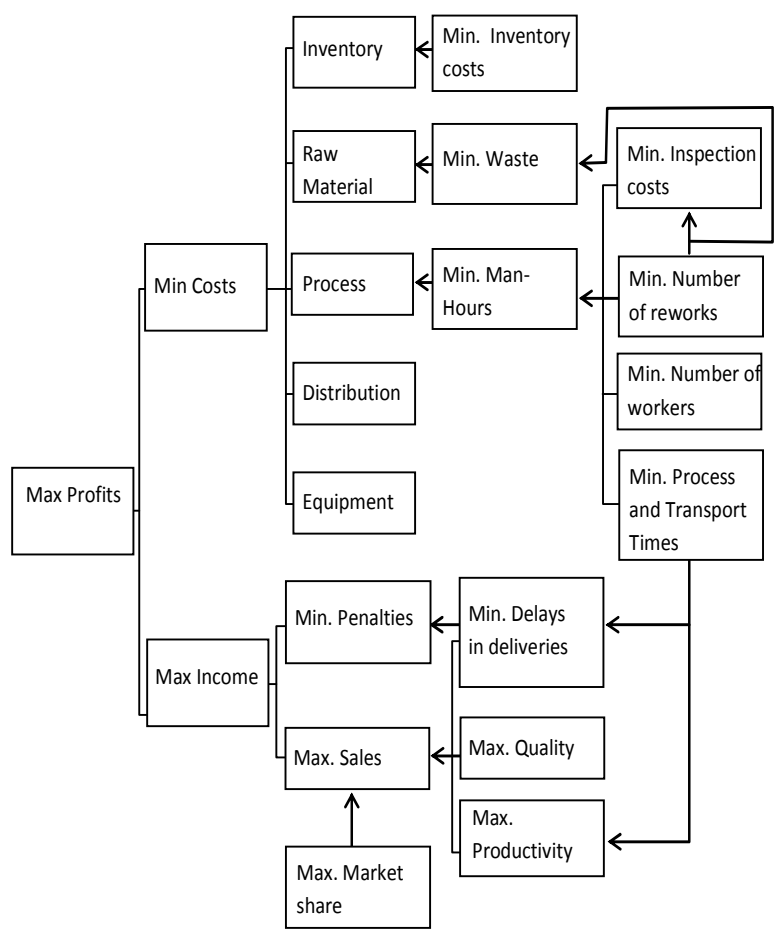

Fig, 5 Mean-Ends Objective Network

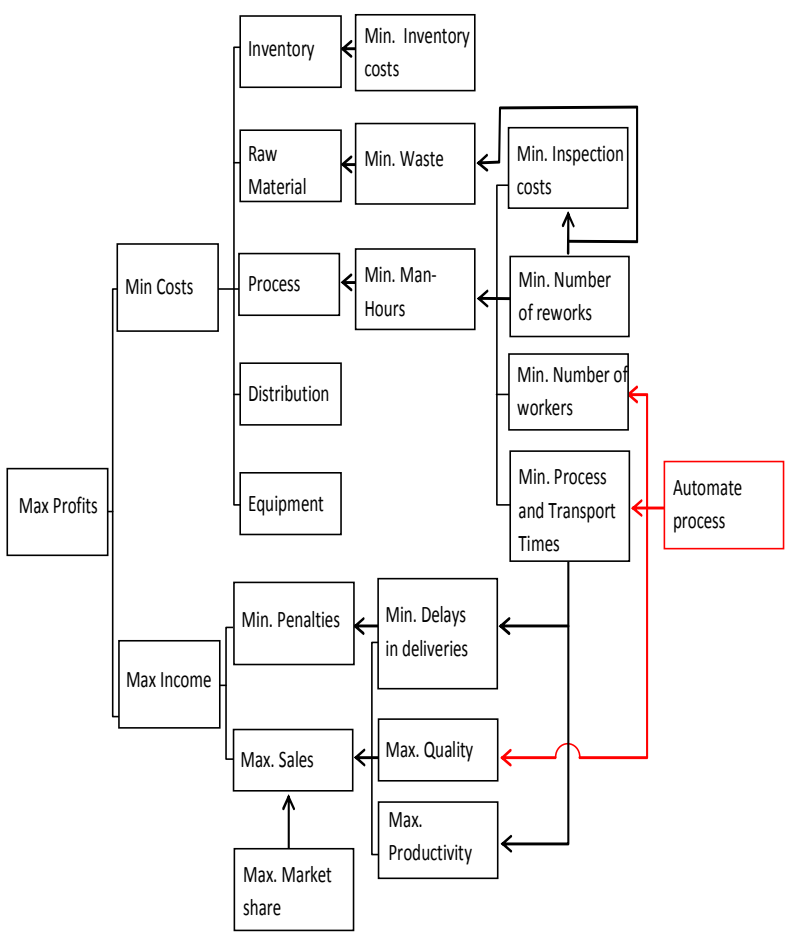

Fig 6. Alternatives and Mean-Ends Objectives Network

\section{Alternatives}

The Means-Ends Objective Network is useful for generating alternatives; however, in this case the class of alternatives to be considered has already been identified by the framing process. The alternative "Automating the process" implies either the introduction of automated machines that substitute the workers in a part of the process or changing the existing machines for new automated ones that require less supervision or fewer workers. This alternative implies purchase, installation, start up and maintenance costs, and, potentially, costs of worker training. To indentify all effects of this alternative on the objectives, we locate the alternative to the right of the Mean-Ends Objective Network and draw arrows to the objectives affected (Figure 6)

Once the general class of alternatives has been set, the following three concrete alternatives are defined for further consideration

1. CNC: Introduce an automatic Lathe.

2. CF: Introduce an automatic Milling Machine.

3. Base: Keep using the current machinery

\section{Analysis of Uncertain Events}

The main uncertainties to be considered can be identified from the Means-Ends Objective Network of Figure 6. The decision should be valued by its economic implications, so we'll need to model the arrow paths that go from "Automate Process" to "Max. Profits". The arrow between "Max. Productivity" and "Max. Sales" and that between "Min. Process and Transport times" and "Max. Productivity" 
represent uncertain relations. While the latter may be dealt with by a simulation model, for the former we will likely have to rely on subjective probabilities from the vendor staff.

\section{E. Decision Modeling}

As the decision should be justified economically, it should be evaluated by its effect on profits

$$
\text { Profits=Income }- \text { Cost }
$$

Income equals the number of tools (vises) sold $N_{V}$ (vises/day) times the selling price of each vise $P_{V}(\$ /$ vise).

$$
\text { Income }=N_{V} \times P_{V}
$$

If $N_{M}$ is the size of the vise market (the maximum number that can be absorbed by the market on a daily basis) and $N_{P R O D}$ the daily production then $N_{V}=\min \left(N_{M}, N_{P R O D}\right)$. The expertise of the company vendors can be used to construct the following contingency table of $N_{V}$.

\section{TABLE I. EXAMPLE OF CONTINGENCY TABLE FOR $N_{V}$}

\begin{tabular}{|c|c|c|}
\hline $\boldsymbol{N}_{\boldsymbol{M}}$ & Probability of $\boldsymbol{n}_{\boldsymbol{M}, \boldsymbol{k}}$ & $\boldsymbol{N}_{\boldsymbol{V}}$ \\
\hline$n_{M .1}$ & $\mathrm{p}\left(n_{M, 1}\right)$ & $n_{M, 1}$ \\
$n_{M .2}$ & $\mathrm{p}\left(n_{M, 2}\right)$ & $n_{M, 2}$ \\
$:$ & $:$ & $:$ \\
$n_{M . \mathrm{i}}$ & $\mathrm{p}\left(n_{M, \mathrm{i}}\right)$ & $n_{M, \mathrm{i}}$ \\
$n_{M . \mathrm{i}+1}$ & $\mathrm{p}\left(n_{M, \mathrm{i}+1}\right)$ & $N_{P R O D}$ \\
$:$ & $:$ & $:$ \\
$n_{M . \mathrm{n}}$ & $\mathrm{p}\left(n_{M, \mathrm{n}}\right)$ & $N_{P R O D}$ \\
\hline
\end{tabular}

Being $n_{M, i}$ such that $n_{M, \mathrm{i}}<N_{P R O D}<n_{M, \mathrm{i}+1}$. The daily costs for each automation option are

$$
\operatorname{Cos} t=\left[\frac{C_{E Q}}{360 \times V_{E Q}}\right]+N_{P R O D} \times\left(C_{M A T}+C_{E N}\right)+C_{M A N}
$$

Where $C_{E Q}$ and $V_{E Q}$ are respectively the total cost and the life span (in years) of the new equipment, $C_{M A T}$ and $C_{E N}$ are the raw material and energy costs of manufacturing one vise. $C_{M A N}$ is the daily staff cost and depends on the number of workers $n_{T}$ and the daily wage $S_{\text {WORK }}$ ( $\$$ day-worker)

$$
C_{M A N}=n_{T} \times S_{W O R K}
$$

If the process is automated, the required number of workers changes, whereas both the automation and number of workers affect the productivity. These relations are uncertain and are modeled as follows: For an automation option, let $N_{P R O D, M A X}$ be the maximum achievable daily productivity. Using the expertise of the plant engineers, a contingency table is elicited, in which different levels of $N_{P R O D}$ are defined as fractions of $N_{P R O D, M A X}$. The table shows, for the relevant automation option, the probability of the $N_{P R O D}$ levels conditional on the number of workers. The structure of such a table is shown in Table 2 , for a high $\left(n_{T, H I G H}\right)$, medium $\left(n_{T, M E D}\right)$ or low $\left(n_{T, \text { LOW }}\right)$ number of workers.
TABLE II. EXAMPLE OF CONDITIONAL PROBABILITIES OF $N_{P R O D}$ FOR A CHOICE OF MACHINERY UPGRADE

\begin{tabular}{|c|l|l|l|l|}
\hline \multicolumn{2}{|c|}{ Number of Workers } \\
\hline \multirow{3}{*}{$N_{P R O D}$} & \multicolumn{2}{|c|}{$\boldsymbol{n}_{T, \text { LOW }}$} & $\boldsymbol{n}_{T, M E D}$ & \multicolumn{1}{c|}{$\boldsymbol{n}_{T, H I G H}$} \\
& $0.8 \times N_{P R O D, M A X}$ & -- & -- & -- \\
& $0.9 \times N_{P R O D, M A X}$ & -- & -- & -- \\
& $N_{P R O D, M A X}$ & -- & -- & -- \\
\hline
\end{tabular}

The actual values of $n_{T, L O W}, n_{T, M E D}$ and $n_{T, H I G H}$ depend on which automation choice is being considered. As summary, an influence diagram of the model is shown in Figure 7. In this diagram rectangles represent decisions; ovals mean uncertain variables and double-bordered ovals stand for deterministic calculations. The value of $N_{P R O D, M A X}$ is obtained by simulating the system for the proposed automation choice. Finally, the risk attitude of the company is introduced by translating the Profits into a utility using an exponential risk averse function (5)

$$
U=1-\exp \left(\frac{\left.{\text { Profit }- \text { Profit }^{0}}_{R}\right)}{R}\right.
$$

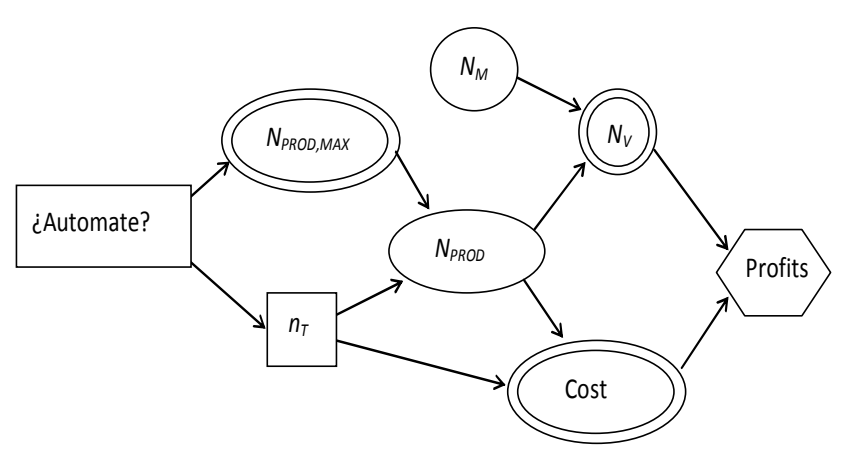

Fig. 7. Influence Diagram for Profits

Profit $^{0}$ is the minimum Profit that can happen and $R$ is the risk tolerance. The alternative to be selected is the one that has the maximum expected utility [43].

\section{F. Assessment of alternatives}

The manufacture of vises, as currently done, is shown in Figure 8 . The name of the operation, the tag of the equipment used, and the mean time (minutes) of the operation are also shown, while the name of each vise part is shown in the arrowlike shapes at the left. To calculate the maximum number of vises produced daily, ARENA [44] simulation models of the original and modified systems were set up.

The model of the CNC option is produced by substituting the lathes (1-M, 2-M, 3-M, 5-M and 7-M) by a single one that processes each part in half the time [45]. The CF option is modeled by taking out the existing milling machines of the model (5-F, 4-F and 3-F) and introducing a single one that can process the parts twice as fast as the formers [46]. The simulated maximum number of vises per day is shown in Table 3 . It is interesting to note that the CNC option did not increase the productivity, as did the CF option. This is because the 
lathes are not an important bottleneck in the process. Probabilities of $N_{P R O D}$ and $N_{V}$, elicited from the plant engineers and vendors, respectively, are shown in Tables 4-7.

TABLE III. SIMULATED $N_{P R O D, M A X}$ FOR CHOICE OF AUTOMATION

\begin{tabular}{|c|c|c|c|}
\hline \multirow{2}{*}{$N_{P R O D, M A X}$} & BASE & CNC & CF \\
\cline { 2 - 4 } & 10 & 10 & 15 \\
\hline
\end{tabular}

TABLE IV. CONDITIONAL PROBABILITIES OF $N_{P R O D}$ FOR BASE CASE

\begin{tabular}{|cc|c|c|c|}
\hline \multicolumn{4}{|c|}{} & \multicolumn{3}{c|}{ Number of Workers } \\
\hline \multirow{3}{*}{$N_{P R O D}$} & $\mathbf{1 0}$ & $\mathbf{1 2}$ & $\mathbf{1 4}$ \\
\cline { 3 - 5 } & $0.6 \times N_{P R O D, M A X}$ & 0.5 & 0.2 & 0.1 \\
& $0.8 \times N_{P R O D, M A X}$ & 0.4 & 0.6 & 0.1 \\
& $N_{P R O D, M A X}$ & 0.1 & 0.2 & 0.8 \\
\hline
\end{tabular}

TABLE V. CONDitional Probabilities of $N_{P R O D}$ FOR UPGRAdE CHOICE "CNC"

\begin{tabular}{|cc|c|c|c|}
\hline \multicolumn{3}{|c|}{} & \multicolumn{3}{|c|}{ Number of Workers } \\
\hline \multirow{3}{*}{$N_{P R O D}$} & $\mathbf{6}$ & $\boldsymbol{8}$ & $\mathbf{1 0}$ \\
\cline { 3 - 5 } & $0.6 \times N_{P R O D, M A X}$ & 0.2 & 0.0 & 0.0 \\
& $0.8 \times N_{P R O D, M A X}$ & 0.3 & 0.3 & 0.1 \\
& $N_{P R O D, M A X}$ & 0.5 & 0.7 & 0.9 \\
\hline
\end{tabular}

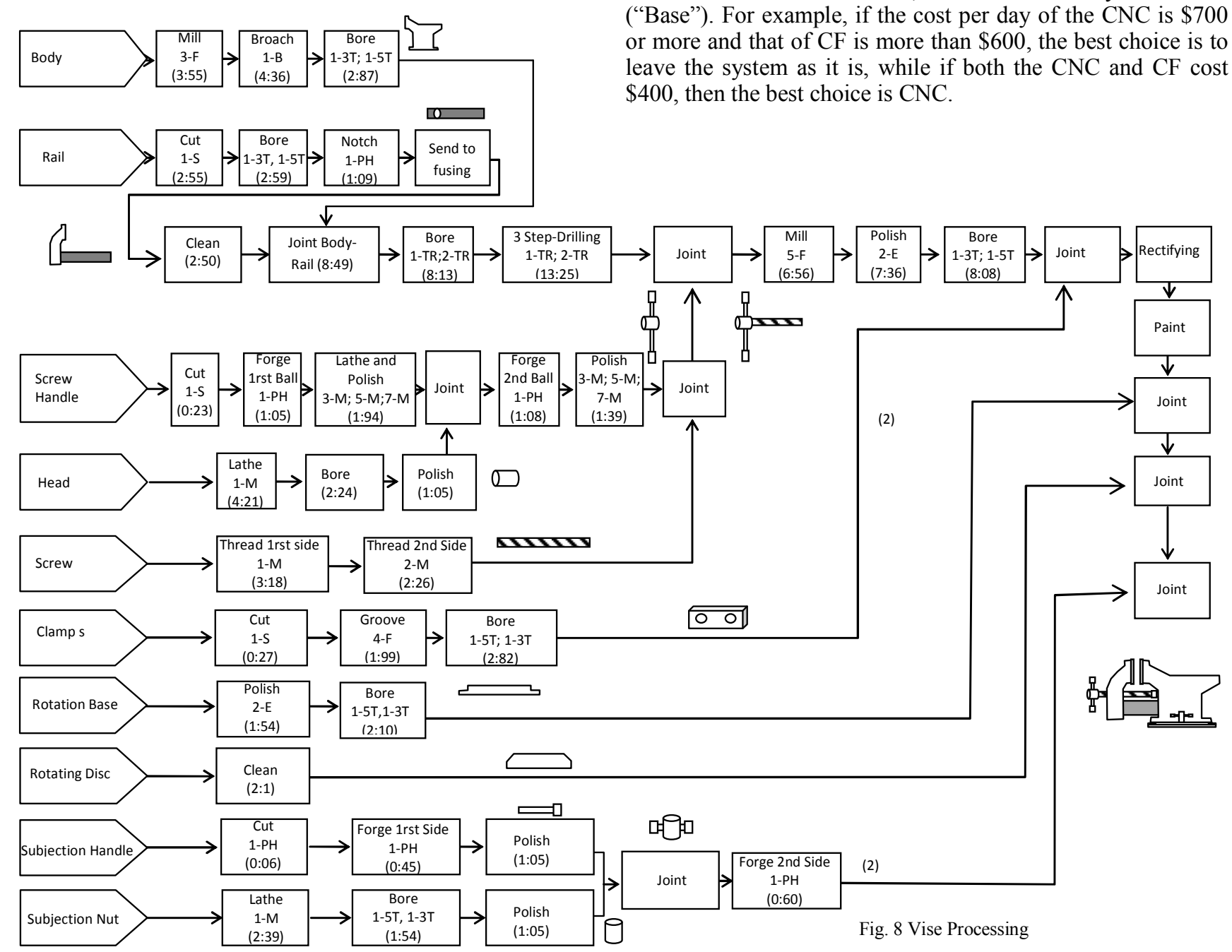

TABLE VI. CONDITIONAL PROBABILITIES OF $N_{P R O D}$ FOR UPGRADE CHOICE "CF"

\begin{tabular}{|cc|c|c|c|}
\hline \multicolumn{4}{|c|}{ Number of Workers } \\
\hline \multirow{4}{*}{$N_{P R O D}$} & $\boldsymbol{8}$ & $\mathbf{1 0}$ & $\mathbf{1 2}$ \\
\cline { 3 - 5 } & $0.6 \times N_{P R O D, M A X}$ & 0.5 & 0.2 & 0.1 \\
& $0.8 \times N_{P R O D, M A X}$ & 0.4 & 0.6 & 0.3 \\
& $N_{P R O D, M A X}$ & 0.1 & 0.2 & 0.6 \\
\hline
\end{tabular}

TABLE VII. PROBABILITY OF VISE MARKET LEVEL

\begin{tabular}{|c|c|}
\hline $\boldsymbol{N}_{\boldsymbol{M}}$ & Probability \\
\hline 6 & 0.2 \\
9 & 0.3 \\
12 & 0.4 \\
15 & 0.1 \\
\hline
\end{tabular}

The values of $P_{V},\left(C_{M A T}+C_{E N}\right), S_{W O R K}$ and $V_{E Q}$ are respectively $\$ 1000, \$ 300, \$ 100$ and 15 years. The risk tolerance $(R)$ was evaluated as $\$ 3000$, using the method in [3].

\section{G. Selection of alternatives}

The results are shown in Figure 9, which is a graph over possible values of equipment cost per day $\left(C_{E Q} / 360 \times V_{E Q}\right)$ for the $\mathrm{CNC}$ and $\mathrm{CF}$ alternatives. The graph shows zones in which the decision should be "CNC", "CF" or leave the system as it is ("Base"). For example, if the cost per day of the CNC is $\$ 700$ or more and that of $\mathrm{CF}$ is more than $\$ 600$, the best choice is to leave the system as it is, while if both the $\mathrm{CNC}$ and $\mathrm{CF}$ cost $\$ 400$, then the best choice is CNC. 


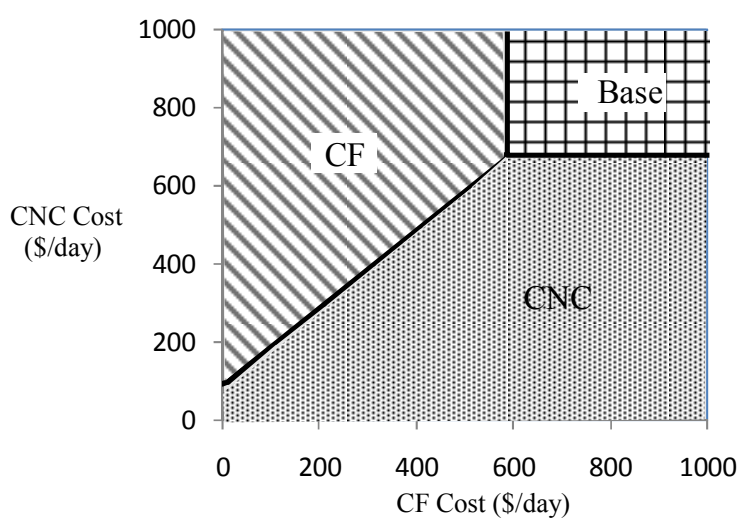

Fig 9. Feasibility zones for choices "CNC", "CF" and "Base"

\section{CONCLUSIONS AND FURTHER WORK}

From the application shown here, it can be concluded that the IDA, proposed by Ley-Borrás [2], is a valuable tool in the clarification and structuring of real life engineering problems. By following its steps, it guarantees that the correct decision is tackled and that the adequate objectives, risk attitude and factual information are included and modeled.

It was also shown how two of the steps of the IDA methodology ("Alternatives" and "Analysis of Uncertain Events") can be improved by using the Means-Ends Objectives Network to identify the relations and uncertainties that should be modeled. Thus, the Means-Ends Objectives Network provides a blueprint for the construction of the decision model.

Currently, the simulation model is being extended with probabilistic vise process times. Also, a decision model that considers decisions about the layout of the workshop simultaneously with decisions of equipment replacement is being developed.

\section{REFERENCES}

[1] R. A. Howard, "Decision analysis: practice and promise", Management Science, Vol. 34, No. 6, pp. 679-695, 1988

[2] R. Ley Borrás, Integral decision analysis, Decision Consulting, 2009

[3] R. T Clemen, Making hard decisions: an introduction to decision analysis, Duxbury Press, 1996

[4] M. D. Resnik, Choices: an introduction to decision theory, University of Minnesota Presss, 2008

[5] J. S. Hammond, R.L. Keeney, H. Raiffa, Smart choices: A Practical Guide to Making Better Life Decisions, Harvard Business School Press, 1999

[6] R. L. Keeney, Value-focused thinking: A Path to Creative Decisionmaking, Harvard Univ. Press. 1992

[7] W. Edwards, R. F. Miles, von Winterfeldt, Advances in decision analysis: From Foundations to Applications, Cambridge University Press, 2007

[8] R. A. Meyer, "Equipment replacement under uncertainty", Management Science, Vol. 17, pp.750-758, 1971

[9] A. G. Bobos, E. N. Protonotarios, "Optimal systems for equipment maintenance and replacement under Markovian deterioration", European Journal of Operational Research, Vol. 2, No. 4, pp. 257-264, 1978

[10] R. Waddell, "A Model for equipment replacement decisions and policies", Interfaces, Vol. 13, No. 4, pp. 1-7, 1983
[11] B. P. Lingaraj, W. Kuo, "An availability model for the evaluation of equipment alternatives", Journal of Operations Management, Vol. 3, No. 3, pp. 149-154, 1983

[12] J. M. A. Tanchoco, L. C. Leung, "An input-output model for equipment replacement decisions", Engineering Costs and Production Economics, Vol. 11, No. 2, pp. 69-78, 1987

[13] N. Ebrahimi, "Two new replacement policies", IEEE Transactions on Reliability, Vol. 42 , No. 1, pp. 141-147, 1993

[14] V. Legát, A. H. Žaludová, V. Červenka, V. Jurča, "Contribution to optimization of preventive replacement", Reliability Engineering \& System Safety, Vol. 51, No. 3, pp. 259-266, 1996

[15] W. G. Sullivan, T. N. McDonald, E. M. Van Aken, "Equipment replacement decisions and lean manufacturing", Robotics and Computer-Integrated Manufacturing, Vol. 18, No. 3-4, pp. 255-265, 2002

[16] M. Chen, C. -Y. Cheng, "Sensitivity analysis for the optimal minimal repair/replacement policies under the framework of markov decision process", IEEE International Conference on Industrial Engineering and Engineering Management, pp. 640 - 644, 2007

[17] X. Cao, A. Jouglet, D. Nace, "A multi-period renewal equipment problem", European Journal of Operational Research, Vol. 218, No. 3, pp. 838-846, 2012

[18] S. K. Nair, W. J. Hopp, "A model for equipment replacement due to technological obsolescence", European Journal of Operational Research, Vol. 63, No. 2, pp. 207-221, 1992

[19] T. Cheevaprawatdomrong, R. L. Smith, "A paradox in equipment replacement under technological improvement", Operations Research Letters, Vol. 31, No. 1, pp. 77-82, 2003

[20] I. E. Schochetman, R. L. Smith, "Infinite horizon optimality criteria for equipment replacement under technological change", Operations Research Letters, Vol. 35, No. 4, pp. 485-492, 2007

[21] E. E. Karsak, E. Tolga, "An overhaul-replacement model for equipment subject to technological change in an inflation-prone economy", International Journal of Production Economics, Vol. 56-57, pp. 291301,1998

[22] R. Pascual, V. Meruane, P. A. Rey, "On the effect of downtime costs and budget constraint on preventive and replacement policies", Reliability Engineering \& System Safety, Vol. 93, No. 1, pp. 144-151, 2008

[23] F. I. D Nodem, J. P. Kenne, A. Gharbi, "A replacement policy of deteriorating production systems subject to imperfect repairs", 3rd IEEE Conference on Industrial Electronics and Applications, ICIEA, pp. 6- 11, 2008

[24] M. Bartholomew-Biggs, M. J. Zuo, X. Li, "Modelling and optimizing sequential imperfect preventive maintenance", Reliability Engineering \& System Safety, Vol. 94, No. 1, pp. 53-62, 2009

[25] R. Pascual, J. H. Ortega, "Optimal replacement and overhaul decisions with imperfect maintenance and warranty contracts", Reliability Engineering \& System Safety, Vol. 91, No. 2, pp. 241-248, 2006

[26] S. Wu, P. Longhurst, "Optimising age-replacement and extended nonrenewing warranty policies in lifecycle costing", International Journal of Production Economics,Vol. 130, No. 2, pp. 262-267, 2011

[27] Y. Pan, M. U. Thomas, "Repair and replacement decisions for warranted products under Markov deterioration", IEEE Transactions on Reliability, Vol. 59 , No. 2, pp. 368-373, 2010

[28] P. -T. Chang, "Fuzzy strategic replacement analysis", European Journal of Operational Research, Vol. 160, No. 2, pp. 532-559, 2005

[29] P. V. Suresh, D. Chaudhuri, B. V. A. Rao, "Fuzzy-set approach to select maintenance strategies for multistate equipment", IEEE Transactions on Reliability, Vol. 43 , No. 3, pp. 451-456, 1994

[30] J. C. Hartman, "Multiple asset replacement analysis under variable utilization and stochastic demand", European Journal of Operational Research, Vol. 159, No. 1, pp. 145-165, 2004

[31] L. C. Leung, J. M. A. Tanchoco, "Multiple machine replacement analysis", Engineering Costs and Production Economics, Vol. 20, No. 3, pp. $265-275,1990$ 
[32] B. Wang, D. Liu, "Rolling horizon procedure for large-scale equipment replacement problems with multiple alternatives", Control and Decision Conference (CCDC), pp. 2741-2746, 2011

[33] I. Nosoohi, S. Reza Hejazi, "A multi-objective approach to simultaneous determination of spare part numbers and preventive replacement times" Applied Mathematical Modelling,Vol. 35, No. 3, pp. 1157-1166, 2011

[34] H. Oeltjenbruns, W. J. Kolarik, R. Schnadt-Kirschner, "Strategic planning in manufacturing systems - AHP application to an equipment replacement decision", International Journal of Production Economics, Vol. 38, No. 2-3, pp. 189-197, 1995

[35] T. W. Sloan, "Green renewal: incorporating environmental factors in equipment replacement decisions under technological change", Journal of Cleaner Production, Vol. 19, No. 2-3, pp. 173-186, 2011

[36] N. C. Suresh, S. Kaparthi, "Flexible automation investments: a synthesis of two multi-objective modeling approaches", Computers \& Industrial Engineering, Vol. 22, No. 3, pp. 257-272, 1992

[37] W. A. Sarache Castro, O. D. Castrillón, G. Gonzales, A. Viveros Folleco, "A multi-criteria application for an equipment replacement decision”, Ingeniería y Desarrollo, Vol. 25, pp. 80-98, 2009

[38] M. Rausch, H. Liao, "Joint Production and Spare Part Inventory Control Strategy Driven by Condition Based Maintenance", IEEE Transactions on Reliability, Vol. 59 , No. 3, pp. 507-516, 2010

[39] S. Arueti, D. Okrent, "A knowledge-based prototype for optimization of preventive maintenance scheduling”, Reliability Engineering \& System Safety, Vol. 30, No. 1-3, pp. 93-114, 1990

[40] G. Avila-Godoy, A. Brau, E. Fernandez-Gaucherand, "Controlled Markov chains with discounted risk-sensitive criteria: applications to machine replacement" Proceedings of the 36th IEEE Conference on Decision and Control, Vol. 2, pp. 1115-1120, 1997

[41] J. M. Fraser, J. W. Posey, "A framework for replacement analysis" European Journal of Operational Research, Vol. 40, No. 1, pp. 43-57, 1989
[42] D. T. Hart, E. D. Cook, "Upgrade versus replacement: a practical guide to decision-making", IEEE Transactions on Industry Applications, Vol. 31 , No. 5, pp. 1136-1139, 1995

[43] R. L Keeney, H. Raiffa, Decisions with multiple objectives: preference and value tradeoffs, John Wiley and Sons, 1998

[44] T. Altiok, B. Melamed, Simulation modeling and analysis with ARENA, Academic Press, 2007

[45] V. Martínez, Modern industrial automation, Alfaomega, 2001

[46] A. García, "Automatic control in industry", Science and Technology Collection, Vol. 48, Universidad de Castilla-La Mancha. 2005

\section{AUTHORS PROFILE}

Mario L. Chew Hernandez was born in México City, on July 27, 1975. He graduated as Chemical Engineer from the National University of México, and holds degrees of $\mathrm{M}$. of Sc. in Process and Project Engineering and $\mathrm{PhD}$ from the University of Nottingham, United Kingdom. He has worked at the Mexican Petroleum Institute and is a full time researcher at the Technological of High Studies of Coacalco. His main interests are applications of Decision Analysis to engineering problems.

Emma K. Velázquez Hernández was born in Tlalmanalco, Mexico, on June 4, 1977. She is an Industrial Engineer from the Technological of High Studies of Chalco and a final year graduate student of Industrial Engineering. She has worked as a process engineer at a tool manufacturer for more that four years. Her interests are application of simulation and decision analysis to improve productivity of the metal-machinery industries.

Salvador León Domínguez was born in Mexico City, on May 28, 1959. He is an Industrial Engineer from the National Politechnic Institute and a final year graduate student of Industrial Engineering. He has more than ten years of experience as process engineer at several manufacturing industries. $\mathrm{He}$ is currently a full time teacher at the Technological of High Studies of Chalco. 